\title{
MigUEL REALE E SEUS RELATOS AUTOBIOGRÁFICOS (1986-1987)
}

\author{
Lucas Patschiki
}

\begin{abstract}
RESUMO
Neste artigo analisaremos os dois volumes autobiográficos de Miguel Reale (19102006), Memórias. Destinos cruzados e Memórias. A balança e a espada, lançados em 1986 e 1987 pela Editora Saraiva, buscando compreender as táticas e as estratégias discursivas utilizadas por ele nesta (re)construção de uma biografia pública. Reale, além de articulador e teórico civil do Golpe de 1964, foi constante colaborador da Ditadura. Durante o processo de reorganização democrática do Estado autocrático-burguês foi assessor jurídico de João Figueiredo, lutando por uma abertura política conservadora, que fosse pautada e compreendida pelo povo como um "presente". Esta proximidade trouxe uma série de questões, pois se Reale não podia renegar os antigos compromissos, não poderia, do mesmo modo, assumir publicamente a defesa do regime. Buscando garantir sua posição de intelectual desenvolveu várias ações articuladas, sendo a principal as edições de suas memórias.
\end{abstract}

Palavras-chave: Autobiografia. Direito. Intelectuais.

\footnotetext{
Doutorando em História na Universidade Federal de Goiás. Brasil. E-mail: lucas.patschiki@gmail.com
} 


\title{
MigUEL REALE AND HIS AUTOBIOGRAPHICAL ACCOUNTS (1986-1987)
}

\begin{abstract}
In this article we will analyze the two autobiographical volumes by Miguel Reale (1910-2006)—Memórias: Destinos cruzados (Memoirs: Crossed destinies) and Memórias: A balança e a espada (Memoirs: The balance and the sword), published in 1986 and 1987 by Editora Saraiva - seeking to understand Reale's tactics and discursive strategies in his (re)construction of a public biography. In addition to being an articulator and civilian theoretician of the 1964 Brazilian coup d'état, Reale was a constant collaborator with the dictatorship. During the process of the democratic reorganization of the autocratic-bourgeois State, Reale was a legal counselor to João Figueiredo. In that capacity, he fought for a conservative political opening to be abided and understood by the people as a "gift." This proximity created numerous issues because if Reale could not deny his old commitments, he could not likewise publicly admit his defense of the regime. Seeking to secure his position as an intellectual, Reale took several coordinated actions, the most important of which was to publish his memoirs.
\end{abstract}

Keywords: Autobiography. Law. Intellectuals.

\section{INTRODUÇÃO}

D ste artigo intenta compartilhar algumas reflexões sobre a experiência histórica de Miguel Reale (1910-2006), a partir dos dois volumes autobiográficos do jurista, Memórias. Destinos cruzados e Memórias. A balança e a espada. Ao deter-nos sobre as memórias de Reale em seus dois volumes autobiográficos publicados entre 1986 e 1987 pela editora Saraiva, empreendemos um primeiro exercício analítico, visando compreender a estratégia de contínua (re)construção que ele empreendia em sua biografia pública, visando a manutenção de sua posição social e status como intelectual. Esta questão se apresenta como hipótese, primeira aproximação de uma investigação que exige ser ampliada.

Abordando os relatos autobiográficos de Reale, a primeira dificuldade é relativa ao recorte temporal: obviamente, nenhuma biografia existe aquém do recorte biográfico do agente histórico investigado (embora para fins analíticos possa, e mesmo em certas investigações deva, ir além deste recorte estrito), mas 
este não é exatamente o caso, já que não se trata de escrever esta biografia, mas de analisar o processo na e pela qual foi produzida. Isso não impede críticas metodológicas, pois ao referir-se a dado relato autobiográfico, iremos inevitavelmente também referir ao tempo de vida do autor, de outro modo, tão somente se apresentaria a descrição do processo produtivo do seu suporte material (no caso, dos livros), ou pior, atribuiria somente para a dimensão discursiva plena capacidade explicativa, arrancando-a (ou melhor, buscando arrancar, pois esta tentativa nunca é plena) de suas determinações históricas.

Assim, analisaremos suas autobiografias em suas "posições de verdade", 0 que as enraíza na segunda metade dos anos 80, nas questões daquele período, com Reale nitidamente preocupado em garantir sua posição de intelectual durante a crise da Ditadura, em sua transição para a forma institucional democrática do Estado autocrático-burguês (FERNANDES, 1976, p. 318-321). Mas, de certa forma assinalamos que suas memórias nos permitem identificar certas "formas" pelas quais Reale conscientemente construía e reconstruía seu passado ao torná-lo público, o ressignificando continuadamente durante toda sua vida pública: suas posições e transformações políticas e ideológicas sempre foram acompanhadas de reinterpretações de sua história, buscando a manutenção de dada "coerência" na produção, exposição e defesa de uma visão de mundo. Sobre as "posições de verdade", elas nos servem como um dos pontos norteadores para uma investigação que caminha entre a história intelectual, a "literatura", e a política:

Vejamos, porém, o que podemos afirmar de modo positivo, no interior de nossa História intelectual, sobre essa fronteira que chamamos de "literatura das ideias", dos textos de intervenção direta no conflito político e social de seu tempo até as expressões dessa forma mais livre e resistente à classificação que é o ensaio, passando pelas obras de caráter sistemático ou doutrinário. 0 elemento comum a todas essas formas do discurso "doxológico" é que a palavra é enunciada a partir de uma posição de verdade, independentemente de quanta ficção se aloje nas linhas desses textos. Pode tratar-se de uma verdade política ou moral, de uma verdade que retire sua autoridade de uma doutrina, da ciência ou de uma intuição mais ou menos profética (ALTAMIRANO, 2007, p. 13-14).

Reale em suas reconstruções discursivas sobre seu passado costumava apresentar "reflexões", reinterpretando suas ações políticas e ideológicas contextualmente (seja frente a novas situações futuras ou passadas), ou seja, 
como cronista de si mesmo, buscava apresentar suas justificativas e suas transformações ideológicas de modo "autorizado" pela sua própria interpretação das diferentes relações de forças históricas que "vivenciou". Esta "estratégia" marcará profundamente sua vida política pós AIB (Ação Integralista Brasileira). John Foster Dulles (1984, p. 230-ss.) nos permite observar esta prática sua já durante a greve estudantil que Reale encara como catedrático da Universidade de São Paulo ao fim do Estado novo. Aqui cabe, além da óbvia constatação de subjetivismo, certa busca ativa de Reale pelo direito de voz no "julgamento da história". Como afirma em texto de 2004, em que traz à tona o famoso episódio do combate entre integralistas e militantes de esquerda (não só comunistas, por sinal) na Praça da Sé em São Paulo, no ano de 1934, onde os integralistas foram escorraçados (quando, segundo o Barão de Itararé, teria sido provado que "galinha verde" não corria, voava):

É fácil, hoje em dia, com a perspectiva histórica que possuímos reconhecer as ilusões e os equívocos da A.I.B., mas os acontecimentos culturais não podem deixar de ser examinados à luz de seu tempo, em função de suas circunstâncias e conjunturas determinantes. Infelizmente, quando se trata de um movimento político da chamada "Direita", há tendência no sentido de denegri-la, enquanto que à "Esquerda" tudo se perdoa, esquecendo-se os genocídios perpetrados por Stalin, e os atos violentos dos brasileiros que, sob a bandeira comunista de Luis Carlos Prestes, tentaram ganhar o poder, como 0 fizeram em 1934, na Praça da Sé, quando, do alto do antigo Edifício Santa Helena fuzilaram a milícia integralista que, desarmada, vestia pela primeira vez a camisa verde, com a morte de dois operários. Sobre esses homicídios nem sequer foi instaurado inquérito policial (REALE, 2004, grifo nosso).

Mas, seja como for, podemos reconhecer que esta ressignificação de sua biografia feita por Reale foi tão eficiente que sua obra intelectual acabou por assumir certa isenção diante de seus posicionamentos políticos e ideológicos, sendo uma das figuras intelectuais mais celebradas publicamente da História recente brasileira, o que talvez explique as divisões que marcam os estudos sobre sua obra e biografia, na academia entre as pesquisas da História e do Direito, além das reinterpretações ideológicas dos neointegralistas. 


\section{OS RELATOS AUTOBIOGRÁFICOS DE REALE}

Suas autobiografias saíram ao fim da década de 80, momento crucial para recuperação e manutenção da posição social de Reale: afinal, desde a sua saída da AIB, primeiro informal, com sua fuga para a Itália após o fracasso da chamada Intentona Integralista (da qual também participaram liberais e outros adversários de Vargas) (CALIL, 2005, p. 179), depois formalmente, quando Plínio Salgado, já em Portugal, nomeou Raymundo Padilha Jr. como seu representante no Brasil, o que Reale considerou quebra hierárquica imperdoável (REALE, 1987b, p. 143144), consolidou-se como "intelectual", estudando na Itália, e na sua volta ao Brasil lecionando e escrevendo sobre Direito. Após duas rápidas passagens pela prisão, ele concorre à cátedra de Filosofia do Direito na USP, concurso atribulado, sendo que sua posse só foi garantida após audiência com Getúlio Vargas no Rio de Janeiro (REALE, 1986, p. 152). Assinalemos, sua condição como intelectual só será garantida pela proximidade e cumplicidade de Reale com os "donos do poder", assumindo plenamente a função de preposto, de funcionário intelectual autorizado da classe dominante. Esta cumplicidade trouxe uma série de questões durante a transição "democrática" da década de 80 , pois se não podia renegar os antigos compromissos, não poderia, do mesmo modo, dar-se ao luxo de assumir publicamente a defesa do regime político em decadência.

Este impasse é "resolvido" em uma série de ações articuladas de Reale. Primeiro, a defesa pública de uma abertura "regulada", através de sua coluna no Estado de S. Paulo (que já mantinha desde seu afastamento do centro golpista após 1964, e que justificou como modo de contribuir para as questões nacionais de modo "autônomo") (REALE, 1986, p. 183), na qual enfatizou sua própria importância no processo, como assessor de João Figueiredo: que a abertura fosse compreendida pelo povo como um "presente" do ditador, e, portanto, posicionando-se contra qualquer movimentação e manifestação popular no processo na medida em que poderiam ou vir a atrasá-lo ou, segundo Reale (o que segundo o ele, de fato veio a acontecer), pior, que as forças populares emergentes, os novos atores em cena, acabassem por não proporcionar tempo suficiente para uma verdadeira discussão sobre o Estado de Direito. Foi este posicionamento que o permitiu manter o mesmo teor ideológico autoritário anterior, sem, contudo, imiscuir-se diretamente na defesa dos negócios da Ditadura: "exatamente por Reale ter substituído a análise pela propaganda, esses textos de intervenção pública [...] são teoricamente tão frágeis e entram em contradição com outras partes de sua obra, citando como exemplo sua interpretação do totalitarismo supostamente existente na Carta de 1988." (FERNANDES, 2006). 
Para Reale foi a precipitação popular que teria feito subsistir uma série de resquícios da Ditadura, utilizando como exemplo a possibilidade do Executivo valer-se de "medidas provisórias" para governar, afirmação do caráter de "totalitarismo normativo" da Constituição (FERNANDES, 2006). A escolha por este exemplo específico é no mínimo irônica, visto que o próprio em 1967, por convite de Costa e Silva, assumiu o Conselho de Alto Nível responsável por reformar a Carta de 1967, a qual previa a elaboração de Decretos-Lei (artigo 49, inciso V), na qual 0 "Presidente da República" (versão jurídica de nossos ditadores), em casos de urgência ou de interesse público relevante, e desde que não resultasse aumento de despesa, podia expedir decretos com força de lei sobre determinadas matérias (artigo 58, I e II). Publicado o texto, com vigência imediata, o Congresso Nacional o aprovava ou rejeitava dentro de sessenta dias. Não podendo emendálos; se, nesse prazo não houvesse deliberação, o texto era tido como aprovado (Parágrafo único do artigo 58). Os pressupostos jurídicos de urgência ou de interesse público relevante daquele texto legal eram muito parecidos com os que hoje vigoram e, mormente pela característica da excepcionalidade, cuja competência "presidencial" para baixar essas medidas era excepcional, assim como é atualmente, tratando-se de medidas provisórias (BRASIL, 1967).

Numa segunda frente, deu-se a reedição do livro $D a$ revolução à democracia (1987a), originalmente lançado logo após o golpe, e agora acrescentada pelos mesmos artigos publicados na imprensa, onde ele defende medidas para a "abertura" política apoiando-se em uma concepção idealista e genérica (mas supostamente histórica) de democracia:

A Democracia, seja ela do tipo liberal ou social, não é produto de uma construção cerebrina, e muito menos o miraculoso resultado de um novo Estatuto político, elaborado desta ou daquela forma [...] a Democracia deve ser 0 resultado de uma experiência, na qual os fatores sociais, econômicos, educacionais, políticos e jurídicos se combinam de maneira complementar [...] Nos países de frágil estrutura econômico-cultural, e até mesmo em países superindustrializados, mas de reduzida "experiência democrática", esta ameaça corrompe-se ou chega a um "ponto de bloqueio", quando a "ação política" ultrapassa determinados limites e, como decorrência de condições endógenas, se converte em "ação subversiva" (REALE, 1987a, p. 144-145). 
Escritos em plena contradição com documentos anteriores de Reale, especialmente quando defendeu existir sob o governo de Médici a mais plena "democracia social", mas "uma ordem democrática ajustada às nossas circunstâncias históricas.” (REALE, 1978, p. 110). Segundo Pádua Fernandes (2006, p. 247):

Enfim, quando Médici situou "o problema político brasileiro em termos de Democracia Social", estaria a referir-se ao legado do liberalismo como "garantia constitucional dos direitos individuais; 0 pluralismo das ideias e dos programas políticos; o consenso dos governados como condição do exercício do poder e a periodicidade de eleições livres, bem como à "função positiva do Estado como fonte de progresso e de cultura, de liberdade e igualdade concretas e efetivas". Esse modelo conteria "o liberalismo e o socialismo democrático", superando-os ${ }^{2}$.

A terceira frente deu-se por uma mudança ideológica anterior, relativa ao projeto de desenvolvimento econômico capitalista adequado ao Brasil, que, se antes se apresentava como defensor do nacional-desenvolvimentismo ${ }^{3}$, agora passa a defender o projeto neoliberal, especialmente em relação ao imperialismo e às empresas estatais. Mas, assinalemos, um neoliberalismo crível, que retoricamente até ratifica o discurso sobre o Estado mínimo, mas que entende perfeitamente as funções deste em relação a uma economia capitalista dependente: "diz-se, em suma, que, com 0 advento da globalização, desapareceu o Estado Nacional, mas há duas razões que demonstram que isto não acontece”, seja porque "o Estado surge como uma razão mínima de relacionamento internacional, por assim dizer, como um ponto de encontro entre o que internacionalmente se ordena", garantia para o imperialismo, ou mesmo por ser "o Estado Nacional é sempre o mínimo de garantia comum da realização do pactuado." (REALE, 2006), garantindo a mediação entre as frações da classe dominante. Em entrevista de 1978, defendeu que "há a necessidade de uma racionalização progressiva dos problemas do Estado. É possível que alguns liberais pensem assim e se intitulem neoliberais" (MOTA, 1981, p. 345).

\footnotetext{
${ }^{2} 0$ autor está citando o livro Política de ontem e de boje de Reale.

${ }^{3}$ Lembrando sua participação no Instituto Brasileiro de Estudos Superiores, do qual foi um dos animadores e membro de seu conselho. Para Reale (1987b, p. 38) o instituto era fundamental para a formação de quadros políticos nacionalistas.
} 
Esta transformação ideológica ocorre após sua contratação como DiretorCoordenador da Light de São Paulo, no ano de 1974, empresa que prestava serviços jurídicos desde 1958, por convite de Antonio Gallotti (ex-AIB), e que inaugura um novo momento de ascensão econômica e social para Reale (passando a acumular a cátedra na USP, o cargo de diretor da Light e seu escritório de serviço de consultoria jurídica e serviços forenses, que também à partir de então passa a ter outro nível de clientela, como os irmãos Matarazzo e 0 Conde Chiquinho Scarpa) (REALE, 1987b, p. 65). "A Light estava vivendo momentos extremamente difíceis, vítima da onda nativista que [...] apontava-a como uma das responsáveis pela subordinação do Brasil ao capital estrangeiro", sendo que admite ter "felizmente, superado essa forma de escapismo" (REALE, 1987b, .p. 60).

Esta influência marca suas atividades posteriores, o que pode ser observado em 1969, quando assumiu novamente a Reitoria da USP (a primeira vez foi em 1949, quando passou nove meses naquele cargo), desta vez indicado por Alfredo Buzaid (também ex-AIB), que tornara-se Ministro da Justiça de Médici, sendo encarregado de implementar a Reforma Universitária, que acabava com as cátedras e formava departamentos colegiados. Em 1972 instaurou o código disciplinar ainda vigente nesta universidade (que ainda possibilita a perseguição contra estudantes, já que proíbe toda e qualquer manifestação política no interior da USP). A influência neoliberal aparece na sua substituição do binômio "Ensino e Pesquisa" por "Ensino, Pesquisa e Extensão", no qual o último preceito foi defendido como a abertura da universidade pública para as iniciativas do mercado, "convênios dos mais fecundos [...] com empresas estatais e particulares", já nesta gestão constituindo "órgãos autônomos, de caráter privado, junto às Unidades", instrumento de mediação "com as forças vivas da economia nacional." (REALE, 1987b, p. 203).

Em 1972, por convite de Mário Gibson Barbosa, então Ministro das Relações Exteriores, assume a tarefa de assessorar juridicamente construção da hidroelétrica de Itaipu (depois fará parte de seu Conselho de Administração). Nota-se os novos posicionamentos ideológicos de Reale, quando insistiu que Itaipu "deveria ser exclusivamente produtora de energia, fazendo entrega desta" (REALE, 1987b, p. 228-229) o que diminuiu o tamanho da empresa estatal, facilitando as posteriores privatizações de diversas transmissoras e distribuidoras de energia regionais.

Este "pioneirismo" o colocará nos anos 80 na "vanguarda" intelectual quando a burguesia encontrava-se em crise de direção. 0 Brasil foi 0 último país 
da América Latina a implantar 0 projeto neoliberal, durante a década de 80 enquanto os demais países latino americanos sofriam com este processo, o Brasil possuía uma conjuntura social marcada por um processo lento e truncado de transição política, contando com um proletariado e campesinato combativos, 0 que foi expresso em acontecimentos como: as cinco greves gerais entre $1983 \mathrm{e}$ 1989; a criação do Movimento dos Trabalhadores Rurais Sem Terra, a consolidação de uma nova central sindical, a Central Única dos Trabalhadores; e um partido de massas, que já na primeira eleição direta para a presidência, em 1989, logrou chegar ao segundo turno, o Partido dos Trabalhadores.

Esse movimento vigoroso que a sociedade elaborou, a partir, sobretudo, dos dias da ditadura, contra ela, empurrando-a no canto da parede, [constituindo] inúmeros movimentos sociais, redefiniu as relações entre Estado e sociedade, vale dizer, as relações de poder [...] De forma geral, houve uma intensa criação democrática por parte da sociedade (OLIVEIRA, 2000, p. 69-70).

Por outro lado, havia uma falta de consenso entre a burguesia nacional em torno de um projeto histórico, o que a eleição de Fernando Collor de Mello acabou proporcionando. Certa "unificação das diversas frações do capital em torno do projeto neoliberal, mesmo com idas e vindas, contradições e disputas internas, em virtude do temor das mesmas de perderem o controle político da sociedade" (FILGUEIRAS, 2006, p. 181-182). Este momento de incapacidade das frações da burguesia articular-se em torno de um projeto histórico tem suas origens na ruptura com o modelo desenvolvimentista, que agrupava diversas frações do capital em torno do Modelo de Substituição de Importações, que até:

[...] o fracasso do Plano Cruzado (1986/1987), predominava entre as distintas frações de classes do bloco dominante a tentativa de redefinir, atualizar e reformar o MSI, mantendo-se ainda um papel fundamental para o Estado no processo de acumulação e desenvolvimento (FILGUEIRAS, 2006, p. 181-182).

A partir da discordância das soluções impostas pelo Estado para a crise, já em 1983 um grupo de economistas começa a se manifestar. "0 afastamento entre empresários e o governo produziu, ao mesmo tempo, uma aproximação dos primeiros aos chamados 'economistas de oposição' ou 'economistas críticos'” 
(BIANCHI, 2004, p. 184-185). Explicitava-se a crítica às ações do Estado, e a defesa de um novo programa desenvolvimentista, com distinções específicas entre os diferentes economistas, "que reservava ao Estado um importante papel, seja nas funções de planejamento, seja nos investimentos estratégicos" (BIANCHI, 2004, p. 184-185). O neoliberalismo já aparecia em cena, em especial através dos Institutos Liberais, mas era minoritário nas discussões. Sobre a atuação do Estado para manter o sistema econômico do período, Francisco de Oliveira (2000, p. 7071) escreveu que:

$\mathrm{Na}$ agonia da ditadura, já ingressando nesse terreno movediço chamado globalização, o Estado das classes dominantes havia sido liquidado financeiramente, até a última gota, para defender a riqueza produzida e apropriada privadamente. A liquidação financeira se fez sob a forma da dívida interna, pública, cujo serviço na verdade sustentava a lucratividade das empresas. Durante toda a década de 80, foram basicamente os lucros não operacionais que sustentaram a lucratividade das grandes empresas no Brasil, todas sem exceção, incluindo as multinacionais; esses lucros não-operacionais, financeiros, decorriam das aplicações nos títulos de dívida pública.

E com o fracasso do Plano Cruzado e dos planos econômicos subsequentes, Bresser e Verão, que "seguiram o mesmo caminho, ou seja, eram planos estritamente de estabilização, apoiados na concepção de inflação inercial e que adotaram a mesma estratégia de combate à inflação - congelamento de preços com mudança da moeda" (FILGUEIRAS, 2006, p. 182), a atuação estatal na contenção da inflação e na volta do crescimento econômico foi fortemente desmoralizada. De modo que, se somando aos embates da Constituinte, que delimitou um avanço para as classes subalternas em seus direitos,

[...] o projeto neoliberal foi se desenhando e se fortalecendo, passando do campo meramente doutrinário para se constituir em um programa político, com a formação de uma percepção, entre as diversas frações do capital, de que a crise tinha um caráter estrutural [e que deste modo] o projeto neodesenvolvimentista era incapaz de responder aos problemas por ela colocados (FILGUEIRAS, 2006, p. 182). 
Assim, caracteriza-se que a "alternativa neoliberal não nasce pronta no interior do empresariado brasileiro. Ela é o resultado de um conflito projetivo que se desenvolveu por vários anos, seguindo uma trajetória nem sempre ascendente", mas histórica, "resultando em uma formulação do projeto neoliberal que está muito longe da versão quimicamente pura preconizada pelos textos doutrinários." (BIANCHI, 2004, p. 200).

Assinalemos que neste período seu filho, Miguel Reale Júnior, já era livredocente da USP (desde 1973, passando a ser professor titular em 1988) e membro do Partido da Social Democracia Brasileira (PSDB), o que o levou em 1983 a integrar o governo de Franco Montoro em São Paulo. Em 1983, tornou-se presidente do Conselho Federal de Entorpecentes (COFEN). Esta posição sem dúvida não só possuiu influência sobre as questões políticas do pai, quanto foi utilizada para a "transição" deste para o novo momento democrático sem grandes acusações públicas em relação a sua atuação na Ditadura.

Por fim, Reale escreve e publica suas memórias, o último prego em seu escudo de defesa contra possíveis detratores (reais ou imaginários). Nestas irá buscar analisar e expor cada uma de suas transformações ideológicas em face tanto às novas questões exigidas pela "história", pela sobrevivência, pela manutenção da nova posição e status social alcançados após assumir a cátedra de Direito da USP. É por esta narrativa exagerada, na qual busca coletar e organizar todas suas conquistas, reais e algumas "meio forçadas", que Miguel Reale faz transparecer plenamente sua atuação como intelectual subalterno a serviço da classe dominante, narrando sua vida entre a aproximação e afastamento do poder, seja da elite política ou dos grupos intelectuais encarregados de intervenção nos rumos econômicos e sociais do país. Esta posição não deixou também de corresponder ao seu lugar na estrutura de classes, isto é, mesmo Reale experimentando ascensão notável, ao mesmo tempo esta se tornou impedimento para que assumisse papel de protagonismo.

\section{CONSIDERAÇÕES FINAIS}

Fruto da divisão e complexificação social do trabalho, o trabalhador intelectual acaba por ter sua importância e reconhecimento na relação que possui

\footnotetext{
${ }^{4}$ Como no mais falacioso dos exemplos, sugere ser ele em parte responsável pela carreira musical de Chico Buarque. Diz o autor: "não exageraria se dissesse que a música desse exímio compositor também nasceu em minha residência [...] ou nas gostosas redes do alpendre da casa de Itanhaém, junto à praia do Sonho." (REALE, 1987b, p. 167).
} 
ou articula em relação à classe dirigente, como produtor de visões de mundo (valores, ideias, representações) responsável pela reprodução da dominação simbólica. Todo grupo social dominante acaba por formar sua própria elite de intelectuais (fraca em capital econômico, forte em capital cultural), já que prevendo a necessidade "de organizar a sociedade em geral, em todo 0 seu complexo organismo de serviços, até o organismo estatal, tendo em vista a necessidade de criar as condições mais favoráveis à expansão da própria classe" (GRAMSCI, 2004, p. 15-16), que acaba por exigir da fração dominante (forte em capital econômico, fraca em capital cultural) a necessidade de dirigir a exploração, acaba por delegar funções para esta fração dominada, escolhendo "'prepostos' (empregados especializados) a quem confiar esta atividade organizativa das relações gerais exteriores à empresa" (GRAMSCI, 2004, p. 15-16), buscando assegurar tanto a unidade da própria fração e classe da qual é expressão quanto para 0 exercício das funções subalternas da hegemonia - "é questão vital não 0 consentimento passivo e indireto, mas o consentimento ativo e direto, ou seja, a participação dos indivíduos, ainda que isto provoque uma aparência de desagregação e de tumulto" (GRAMSCI, 2002, p. 333).

Para a compreensão da trajetória de vida pública de Reale, passível de ser traçada em linhas gerais através das suas memórias, nos é indispensável 0 conceito de intelectual orgânico: de outro modo não poderíamos explicar suas transformações ideológicas, seu transformismo. Segundo Gramsci 0 transformismo pode ser definido como a "absorção gradual mas contínua, e obtida com métodos de variada eficácia, dos elementos ativos surgidos dos grupos aliados e mesmo dos adversários e que pareciam irreconciliavelmente inimigos" (GRAMSCI, 2002, v. 5, p. 63). A relação com a fabricação do consenso hegemônico, "a fase mais estritamente política, que assinala a passagem nítida da estrutura para a esfera das superestruturas complexas; é a fase em que as ideologias geradas anteriormente se transformam em 'partido'", é o momento de disputa onde uma destas ideologias (ou uma combinação) prevalece, assegurando o domínio de uma fração da classe dominante sobre esta, visando seu consenso intraclassse, e o convencimento ativo dos dominados, "determinando, além da unicidade dos fins econômicos e políticos, também a unidade intelectual e moral." (GRAMSCI, 2002, v. 3, p. 41). Neste sentido, os intelectuais, funcionários da superestrutura, também sofrem uma hierarquização específica (no campo, relativo ao seu capital cultural) (BOURDIEU, 2002, p. 5) e pela sua função social: em disputa marcada pela necessidade desta "classe subordinar/coordenar classes aliadas ou inimigas" (DIAS, 2006, p. 61). 
No Brasil, um país cujo desenvolvimento histórico do Estado é marcado pela revolução passiva, pelo seu caráter autocrático-burguês, a figura do intelectual "público" nunca chegou a alcançar o status que obteve em outras formações sociais. Como as rupturas históricas no Brasil sempre ocorreram pela lógica da pela conciliação das frações da classe dominante, o espaço de atuação pública dos intelectuais sempre foi diminuto. Por sinal, o que se verifica é a disputa entre grande parte dos intelectuais tradicionais para cumprir o papel de representantes autorizados da fração avançada da burguesia, organizadores da hegemonia. Esta lógica corrobora a verificada por Gramsci, quando dizia que a principal atividade dos intelectuais orgânicos era a assimilação e conquista ideológica dos intelectuais tradicionais (GRAMSCI, 2004, p. 19), mas que só pode ser plenamente decifrada levando-se em plena consideração 0 desenvolvimento das estruturas de poder nacionais, que atentam para desmistificar qualquer "autonomia" que possa ser imaginada neste cenário, especialmente em relação à Universidade. Como afirma Luciano Martins (2000): "desde seu nascimento, a universidade é concebida mais como um instrumento político do que propriamente como um lugar de produção científica; e, o que é mais importante, o Estado intervém no campo cultural antes de que este se estruture."

Neste sentido podemos sem nenhum problema classificar Miguel Reale como um intelectual menor, em disputa constante para manutenção de sua posição e status social como "porta-voz" de um poder que nunca deteve, e que ainda teve de "retroceder" nesta lógica para garantir sua posição social, sendo que todas suas tentativas de novamente passar de "especialista" para "dirigente" (GRAMSCI, 2004, p. 53), como político autorizado da classe dominante, foram frustradas, para ver-se negado pelo seu passado, quando assumiu-se política e ideologicamente frente a AIB, na década de 30, expressão da pequena burguesia e da nova pequena burguesia brasileira (CALIL, 2005, p. 122-196). Entre os diversos exemplos referentes às suas memórias, três momentos são interessantes: 0 primeiro relativo à sempre negada vontade sua de ser governador do Estado de São Paulo, que só teria superado por intervenção direta de Dona Nuce, sua esposa. "Devo a Nuce o descortino de novos horizontes, com o superamento total da crise que atormentava meu espírito". Dona Nuce observando-o "abatido e desconsolado", teria feito uma pergunta que o deixou perplexo: "Você, que se queixa tanto de não ter sido governador, sabe me dizer quais foram eles em São Paulo há trinta anos?". Como este não soube a responder, "ela foi quase rude": "Então, deixe de lado a política e pense em si mesmo". (REALE, 1987b, p. 2). 0 segundo refere-se ao seu isolamento após o Golpe de 64, quando escreveu que "minha palavra soou no deserto e o Poder, o Poder Revolucionário, desimantado 
de uma Idéia diretora, só podia, com o desgaste do tempo, sofrer o desfecho que tem todo regime autoritário, comprometido pelos que eu apelidava de "farsantes de $1^{\circ}$. de abril" (REALE, 1987b, p. 141). Nos dois casos encontrou "refúgio" na atividade intelectual, "diante do vazio político criado pelo regime militar, não me restou senão engolfar-me em meus estudos e pesquisas" (REALE, 1987b, 249).

0 terceiro caso é muito mais marcante na sua vida política: sua expulsão da Convenção do Partido Social Progressista em 1950, do qual foi um dos fundadores (e responsável pelo seu manifesto). Quando seu o nome foi indicado para a sucessão estadual, Adhemar de Barros, que apoiava Lucas Nogueira Garcez (seu Secretário de Viação e Obras públicas), em alegada parceria com o Secretário de Segurança Pública e do Delegado da Ordem Política e Social manda prender correligionários nos dias anteriores da Convenção, sob a alegação de estar em curso um "golpe integralista". Na imprensa, a saída de Reale da convenção foi apresentada como motivada pela discordância da mesa que a presidia em fazer a votação para os elegíveis de maneira secreta (CANDIDATO..., 1950), mas no dia seguinte, em entrevista ele afirmava que sua retirada da convenção se deu pelo desrespeito a democracia interna do partido: "agentes da polícia política começaram a interferir, arrancando os meus cartazes e chegando ao cúmulo de prender 0 presidente de um diretório, sem contar uma caminhonete de estudantes e material de propaganda." (POSSO..., 1950, p. 6).

Esta situação de "quase transição" entra as duas posições aparece em suas biografias como frustração. Reale esteve muito próximo do poder político, especialmente nos momentos de crise, quando a burguesia se viu obrigada a firmar alianças mais ou menos temporárias com a pequena burguesia e com a nova pequena burguesia, mas que nunca colheram os frutos que lhes foram prometidos. Seu comprometimento, por vezes excessivo, nunca recebeu a "devida atenção", motivo de ampla frustração, parte do que Poulantzas (1975, p. 221-227) preferiu chamar da "eterna crise" dos estratos médios da sociedade. Neste sentido podemos compreender o "sofrimento" sem miséria de Reale em suas memórias, seu constante refazer-se biográfico, justificativa e garantia de dada coerência pessoal em suas transformações ideológicas frente às novas exigências do poder. 


\section{REFERÊNCIAS}

ALTAMIRANO, Carlos. Idéias para um programa de história intelectual. Tempo Social, São Paulo, v. 19, n. 1, 2007.

BIANCHI, Álvaro Gabriel. O ministério dos industriais. A Federação das Indústrias do Estado de São Paulo na crise das décadas de 1980 e 1990. 2004. Tese (Doutorado em Ciências Sociais) - UNICAMP, Campinas, 2004.

BOURDIEU, Pierre. Campo de poder, campo intelectual: itinerario de un concepto. Buenos Aires: Montressor, 2002.

BRASIL. Constituição da República Federativa do Brasil de 1967. Disponível em: <http://www.planalto.gov.br/ccivil_03/constituicao/constituica067.htm>. Acesso em: 22 jan. 2013.

CALIL, Gilberto Grassi. O integralismo no processo político brasileiro - o PRP entre 1945 e 1965: cães de guarda da ordem burguesa. 2005. Tese (Doutorado em História) - UFF/UNIOESTE, Niterói, 2005.

CANDIDATO do P.S.P. ao governo do Estado o Sr. Lucas Nogueira Garcez. Folha da Manhã, n. 8.049, 27 jun. 1950. Capa.

DIAS, Edmundo Fernandes. Política brasileira: embate de projetos hegemônicos. São Paulo: Instituto José Luís e Rosa Sundermann, 2006.

DULLES, John Foster. Reale enfrenta os estudantes. In: DULLES, John Foster. A faculdade de direito de São Paulo e a resistência anti-Vargas: 1938-1945. Rio de Janeiro: Nova Fronteira; São Paulo: EDUSP, 1984. p. 223-276.

FERNANDES, Florestan. A revolução burguesa no Brasil. Rio de Janeiro: Zahar, 1976.

FERNANDES, Pádua. A cultura jurídica brasileira e a chibata: Miguel Reale e a história como fonte do direito. Prisma Jurídico, São Paulo, v. 5, 2006. Disponível em:

<http://www.uninove.br/PDFs/Publicacoes/prisma_juridico/pjuridico_v5/prismaj _v5_3m30.pdf $>$. Acesso em: 22 jan. 2013.

FILGUEIRAS, Luiz Antonio Matttos. 0 neoliberalismo no Brasil: estrutura, dinâmica e ajuste do modelo econômico. In: BASUALDO, Eduardo M.; ARCE0, Enrique. Neoliberalismo $y$ sectores dominantes: tendencias globales y experiencias nacionales. Buenos Aires: Conselho Latinoamericano de Ciencias Sociales, 2006. p. 179-206. 
GRAMSCI, Antonio. Cadernos do cárcere. Rio de Janeiro: Civilização Brasileira, 2004. v. 2.

GRAMSCI, Antonio. Cadernos do cárcere. Rio de Janeiro: Civilização Brasileira, 2002. v. 3, 5 .

MARTINS, Luciano. A gênese de uma intelligentsia. Os intelectuais e a política no Brasil 1920 a 1940. Revista Brasileira de Ciências Sociais, São Paulo, n. 4, 2000. Disponível em: <http://www.anpocs.org.br/portal/publicacoes/rbcs_00_04/rbcs04_06.htm > . Acesso em: 19 mar. 2012.

MOTA, Lourenço Dantas et al. 0 risco é inerente à democracia. Entrevista com Miguel Reale. 14 maio1978. In: MOTA, Lourenço Dantas (Coord.). História vivida. São Paulo: 0 Estado de S. Paulo, 1981. v. 1, p. 345.

OLIVEIRA, Francisco de. À sombra do manifesto comunista. In: SADER, Emir; GENTILI, Pablo (Org.). Pós-neoliberalismo II: que Estado para que democracia? Petrópolis: Vozes, 2000. p. 68-78.

POULANTZAS, Nicos. As classes sociais no capitalismo de boje. Rio de Janeiro: Zahar Editores, 1975.

POSSO ter todos os defeitos, menos o de curvar-me diante de injunções. Expõe 0 Prof. Miguel Reale as razões que o levaram à dissidência. Folha da Manhã, n. 8.050, 28 jun. 1950.

REALE, Miguel. A realidade do Estado nacional. 2006. Disponível em: $<$ http://miguelreale.com.br> . Acesso em: 22 jan. 2013.

REALE, Miguel. Da revolução à democracia. São Paulo: Convívio, 1987a.

REALE, Miguel. Memórias: a balança e a espada. São Paulo: Saraiva, 1987b. v. 2.

REALE, Miguel. Memórias: destinos cruzados. São Paulo: Saraiva, 1986. v. 1.

REALE, Miguel. O integralismo revisitado. 2004. Disponível em: $<$ http://miguelreale.com.br > . Acesso em: 21 jan. 2013.

REALE, Miguel. Política de ontem e de hoje. São Paulo: Saraiva, 1978. 